Short communication

\title{
ACTH $_{4-10}$ ANTAGONISM OF MORPHINE-INDUCED BEHAVIORAL ACTIVATION IN THE MOUSE
}

\author{
RICHARD J. KATZ
}

Mental Health Research Institute, Department of Psychiatry, University of Michigan Medical Center, Ann Arbor, MI 48109, U.S.A.

Received 14 November 1978, accepted 17 November 1978

R.J. KATZ, $A C T H_{4-10}$ antagonism of morphine-induced behavioral activation in the mouse, European J. Pharmacol. 53 (1.979) $383-385$.

The 4-10 fragment of adrenocorticotrophic hormone $\left(\mathrm{ACTH}_{4-10}\right.$; Met-Glu-His-Phe-Arg-Trp-Gly) was administered intracerebroventricularly to $\mathrm{C57} \mathbf{B l}$ mice with and without concurrent systemic injection of a standard dose of morphine sulfate. Morphine produced stereotyped behavioral activation (running, environmental oblivion, Straub tail) which was antagonized in a dose related fashion by the ACTH fragment. This extends the range of opiate- $\mathrm{ACTH}_{4-1}$ interactions to a novel species and behavioral model, and is consistent with previous findings.

$\mathrm{ACTH}_{4-10}$ Behavioral activation Morphine Psychomotor activity

\section{Introduction}

Gispen, Terenius, and colleagues have demonstrated that fragments of ACTH which posess no intrinsic stimulating activity for the adrenal cortex are nonetheless active in a variety of situations involving opiates. The 4-10 peptide for example is known to antagonize opiate binding and analgesia in at least one species, the rat (summarized in Gispen et al., 1977). Opiates and enkephalins produce profound behavioral excitation in mice, characterized by continual stereotyped horizontal motor activity, environmental oblivion, and Straub tail elevation (e.g. Katz et al., 1978). To further examine ACTH-opiate interactions in a novel species and behavioral model, we injected mice with' a standard behaviorally effective dose of morphine and varying doses of $\mathrm{ACTH}_{4-10}$. The ACTH fragment reduced running in a dose related manner suggesting considerable behavioral generality for previously established findings.

\section{Materials and methods}

\subsection{Subjects}

60 adult male C57Bl/2J mice 25-35 g each (Jackson Laboratories Inc., Bar Harbor, ME) were group housed 6/cage with food (Tedlad $4.0 \%$ fat diet S-0836; Teklad, Inc., Madison, WI) and tap water continuously available. Day/night cycles of $12 \mathrm{~h} / 12 \mathrm{~h}$ (lights on = $8.00-20.00 \mathrm{~h}$ ) were automatically programmed.

\subsection{Surgery}

Each mouse was anesthetized with $50-80$ $\mathrm{mg} / \mathrm{kg}$ sodium pentobarbital (Nembutal) and stereotaxically implanted with a 23 ga/stainless steel cannula aimed at the lateral ventricle. The cannula was mounted on the skull with acrylic dental cement and stainless steel screws. Additional details of surgery and cannula construction have been previously pre- 
sented (Katz et al., 1978). A minimum of 4 days recovery preceded further experimental procedures.

\subsection{Apparatus and behavioral procedure}

The field sensitive activity monitors used to measure locomotion (Stoelting, Chicago) have been described previously (Katz et al., 1978). Subjects were individually placed in $51 \times 41 \times 22 \mathrm{~cm}$ polypropylene cages (Scientific Products series 70) with a fresh pine chip bedding and allowed to habituate until 20 min without activity as registered upon the sensors. Each mouse was then briefly removed from the apparatus and centrally and systemically injected with drug or vehicle. Central injection was by a manually operated Hamilton microsyringe with infusion times of $30 \mathrm{sec}$ or less. Systemic injections were intraperitoneal. Activity was then recorded for 21 consecutive 10 min periods.

\subsection{Drugs}

Morphine sulfate was injected $50 \mathrm{mg} / \mathrm{kg}$ in a sterile $0.9 \%$ sodium chloride vehicle in a 10 $\mathrm{ml} / \mathrm{kg}$ injection volume. $\mathrm{ACTH}_{4-10}$ (Peninsula No. 8750, San Carlos, CA) was injected 0, 7.5 or $15 \mu \mathrm{g}$ in a $5.0 \mu \mathrm{l}$ of Ringer-Locke solution. The compound was prepared within $48 \mathrm{~h}$ of use and stored at $4.0^{\circ} \mathrm{C}$ until injection.

\section{Results}

All results are presented in fig. 1 as mean and standard error. The findings were analyzed using two way analysis of variance with repeated measures on time. By this technique the main drug effects were significant. F groups $=14.1$ d.f. $=5,54 \mathrm{P}<0.01 ; \mathrm{F}$ time $=$ 8.7 d.f. $=20,981 \mathrm{P}<0.01 ; \mathrm{F}$ interaction $=$ 11.8 d.f. $=100,981 \mathrm{P}<0.01$. Further comparisons by Duncan's test indicated significant differences between morphine and control, and two ACTH-morphine groups and the

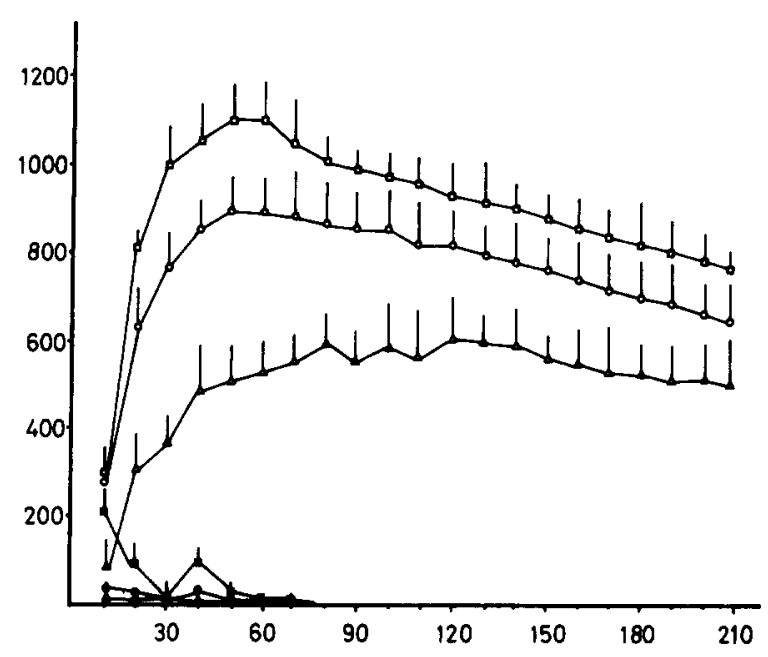

Fig. 1. Effect of $\mathrm{ACTH}_{4-10}$ upon morphine-induced behavioral activation in the mouse. Note all open symbols are morphine-injected, all closed symbols vehicle-injected. Ordinate: mean activity/10 min \pm S.E.M.; abscissa: time ( $\mathrm{min}$ ). Dose of ACTH: squares, $0 \mu \mathrm{g}$; circles: $7.5 \mu \mathrm{g}$; triangles: $15.0 \mu \mathrm{g}$. Dose of morphine: solid symbols, none; open symbols, $50 \mathrm{mg} / \mathrm{kg}$. $n=10 /$ group.

morphine alone group. Therefore, the morphine treatment produced an increased activity which was significantly reduced by the peptide pretreatment.

\section{Discussion}

The present findings extend previous reports to a novel species and behavioral paradigm. The results confirm previous findings and suggest considerable generality to the behavioral interactions of opiates and $\mathrm{ACTH}_{4-10}$. The route of administration of the latter and an absence of established adrenocorticotrophic effects points to a central mediation. Both ACTH and endorphins are contained within the structure of $\beta$-lipotropin which may be a naturally occurring parent compound for ACTH and endorphins (Guillemin et al., 1977). Therefore, both previous and present studies may point to a normal biological control of activation and behavior by peptides concomitantly released during stress. 


\section{Acknowledgements}

Supported in part by postdoctoral grant MH07417 from the National Institute of Mental Health through the Mental Health Research Institute. Gratitude is expressed to Giulio Baldrighi who designed the cannula system and performed the bulk of surgery, and to Mary Sies for editorial assistance.

\section{References}

Gispen, W.H., M.E.A. Reith, P. Schotman, V.W. Wiegant, H. Zwiers and D. De Wied, 1977, CNS and ACTH like peptides: Neurochemical response and interaction with opiates, in: Neuropeptide Influences on Brain and Behavior, eds. L.H. Miller, C.A. Sandman and A.J. Kastin (Raven Press, New York) p. 61.

Guillemin, R., T. Vargo, J. Rossier, S. Minick, N. Ling, C. Rivier, W. Vale and F. Bloom, 1977, $\beta$-Endorphin and adrenocorticotropin are secreted concomitantly by the pituitary gland, Science $197,1367$.

Katz, R.J., B.J. Carroll and G. Baldrighi, 1978, Behavioral activation by enkephalins in mice, Pharmacol. Biochem. Behav. 8, 493. 